\title{
A Comparative Study of Conceptual Metaphors in English and Chinese Economic News Headlines
}

\author{
Lifen Gao \\ School of Foreign Languages, Yangtze University, Jingzhou, China \\ Email:18990132@qq.com
}

How to cite this paper: Gao, L. F. (2016). A Comparative Study of Conceptual Metaphors in English and Chinese Economic News Headlines. Creative Education, 7, 26292639.

http://dx.doi.org/10.4236/ce.2016.717247

Received: October 10, 2016

Accepted: November 8, 2016

Published: November 11, 2016

Copyright $\odot 2016$ by author and Scientific Research Publishing Inc. This work is licensed under the Creative Commons Attribution International License (CC BY 4.0).

http://creativecommons.org/licenses/by/4.0/

\begin{abstract}
This paper is aimed to comparatively analyze metaphors in English and Chinese economic news headlines, to announce the pervasiveness of metaphors in economic news headline and to find out the similarities and differences of conceptual metaphors between English and Chinese. Due to the common cognitive basis, the submetaphors are basically the same in the presence of Chinese and English news headlines. However, conceptual metaphors vary from Chinese to English news deadlines because of the different cultural, natural, and physical environment. Therefore, it is necessary to take these factors into account when understanding Chinese and English news headlines.
\end{abstract}

\section{Keywords}

Conceptual Metaphor, Economic News Headlines, Comparative Study

\section{Introduction}

Metaphor has been a heated topic of linguistic study. In the traditional theory, metaphor is considered as merely a literary matter, a rhetorical device, and a decoration of language. The conceptual metaphor theory, put forward by Lokaff and Johnson (Lakoff \& Johnson, 1980) and receiving great attention and recognition in the world, holds that metaphor is not only a kind of rhetorical device but also a general thinking mode as well as a way of cognition by which people understand the unknown things through the known.

Nowadays, economy is getting closely related to our life, and economy articles are often flooded with metaphors. As the summary of the news reports, headlines play a significant role in acquainting readers with the main points of the news. The headlines are regarded as "the eyes of news report". Some people believe that by using concise 
and informative vocabularies, as well as proper and vivid use of rhetorical devices, such as metaphor, the gist of a news report can be efficiently received and perceived by readers. Thus it would serve the purpose of acquainting people with a good supply of events happening every day efficiently and effectively. However, in recent years, metaphors that appear in news headlines are no long considered as "rhetorical device", and we have to admit that when we read a metaphor, it is an image or idea rather than a word or letter that conjures in our mind.

Despite a great number of metaphor studies in the economic field in the past decades (McCloskey, 1983, 1990; Henderson, 1982, 1986), few scholars have ever extended their research to the comparative study on the deadlines of Chinese and English economic news. During recent years, although a lot of research of news headlines in economic field has been done by many scholars (Boers, 2000; Koller, 2004, 2008), there is still some space for the current study with updated materials, and this study will promote diversity in the finance field and the explanations for the similarities and differences make it easier to understand some abstract concepts in economic news headlines, which will have a positive impact on language learning. Therefore, to explore the similarities and differences is of great significance and can help readers better grasp the gist of an economic news report.

This article consists of the following four parts. The first part presents the theoretical gist, introducing the theoretical framework and making people know better of the conceptual metaphor theory, its definition and its classification. The second part is the core, classifying dozens of subcategories according to the source domains under the conceptual metaphor theory and making a comparison in order to find the similarities and differences between metaphors in English and Chinese economic news headlines with the support of many examples. The third part explores the reason for the similarities and difference between English and Chinese conceptual metaphors from historical, cultural and environmental perspectives. The fourth part serves as the conclusion, summarizing the results and the factors of similarities and differences.

\section{Definition and Classification of Conceptual Metaphor}

The English word "metaphor" derives from word "metaphora" in Creek, in which "meta" means "to cross", and "phor" is "to carry", so the whole word means to transfer from one thing to another. Traditionally, metaphor is regarded as a matter of language. The scholars in different times propose different theories to understand metaphor. Since Metaphor We Lived By (Lakoff \& Johnson, 1980) is published, scholars have set their focus on the cognitive nature of metaphor.

Different scholars give different classifications from their perspectives. In accordance with the differences in source domain, Lakoff \& Johnson (2003) claimed that conceptual metaphors can generally be divided into three main types: structural metaphors, ontological metaphors and orientational metaphors.

1) Structural metaphor

Structural metaphors refer to those concepts that are understood and expressed in 
terms of another well-structured concept. In other words, structural metaphor capacitates speakers to understand target domain by means of the structure of the source domain. Lakoff and Johnson put forward a typical example ARGUMENT IS WAR in the book Metaphors We Live By (Lakoff \& Johnson, 1980: p. 4), and list various expressions in our daily life to show how structural metaphor is identified and used in cognitive activity:

The concept of ARGUMENT and the structural metaphor ARGUMENT IS WAR

- Her statements are indefensible.

- I attacked every weak point in his statement.

- You disagree? Okay, shoot!

- He shot down all my points.

(Lakoff \& Johnson, 1980)

Here we talk about arguments in terms of war, we can win or lose in a war, likewise we can win or lose in the argument. The person we talk with is seen as our opponent in a war, so we challenge his arguments to defend ourselves.

2) Ontological metaphor

In the ontological metaphor, events, activities or something abstract are seen as entities or concrete substances. It can be further divided into entity and substance metaphor, container metaphor and personification (Lakoff \& Johnson, 1980: p. 26).

\subsection{Inflation Is an Entity}

- If there is much more inflation, we will never survive.

- We need to combat inflation.

- Inflation makes me sick.

According to Lakoff \& Johnson, "viewing inflation as an entity allows us to see it as a cause, identify a particular aspect of it and have certain feelings in accordance with it" (Lakoff \& Johnson, 2003: p. 28). In this way, the conception towards abstract concept or word is easy to understand.

3) Orientational metaphor

Orientational metaphors are closely related to human beings' most basic living experiences. Lakoff and Johnson consider that most orientational metaphors have some relationships with spatial orientation, such as up-down, in-out, front-back, on-off, deepshallow and etc. These spatial orientations originate from the fact that human beings have certain physical shape, which has some functions in our environment. Lakoff and Johnson (1980: p. 14) further point out that these orientational metaphors are not arbitrary, but are based on our physical and cultural experiences.

Human beings often use these orientation concepts to understand more abstract concepts such as quantity, emotions, physical condition, social status, value and so on. Take the very typical up-down metaphor as an example:

\subsection{Happy Is Up; Sad Is Down}

- I'm feeling up. 
- I'm feeling down.

- HEALTHY IS UP; SICK IS DOWN

- He's in top shape.

- His health is declining.

Based on the above examples, Lakoff and Johnson come to the conclusion that orientational metaphors give a concept a spatial orientation, and our most basic concepts are arranged in terms of orientational metaphors, and every orientational metaphor has its own interior systematicity. Lakoff and Johnson (1980: p. 19) think that "A metaphor cannot be understood or fully expressed without the experiential basis".

\section{Metaphors in English and Chinese Economic News Headlines}

Since a growing number of scholars learn and study metaphor nowadays, we can easily tell some of the subcategories, such as WAR METAPHOR, UP-DOWN METAPHOR, CONTAINER METAPHOR, HUMAN METAPHOR, JOURNEY METAPHOR and the like.

According to the source domain, we classify the metaphorical expressions into the following subcategories.

Structural Metaphor: Journey Metaphor, War Metaphor, Nature Metaphor, Love \& Marriage Metaphor, Medicine Metaphor, Food Metaphor, Religion Metaphor, Game Metaphor, Drama Metaphor and ect.

Ontological Metaphor: Human Metaphor, Container Metaphor, and Entity and substance Metaphor.

Orientational Metaphor: Up-down Metaphor and so on.

\subsection{The Same Subcategories of Conceptual Metaphors in Both Chinese and English Economic News Headlines}

\subsubsection{Journey Metaphor}

Journey metaphor is a widely-used metaphor, which is firstly studied by Lakoff \& Jonson regarding love. The two scholars think both English and Chinese economic news headlines share the common metaphor "Economy is a journey. On the basis of person's experience in life, a journey means traveling from one place to another, and usually people would associate journey with the departure, path and destination. According to Lakoff s cross-mapping theory,when economy is depicted as a journey, it means that all the features of source domain, "journey", is systematically mapped onto the target domain "economy". More often than not, the impression of journey is set as an action of overcoming difficulties along the rode on the way to the destination. The correspondence between journey and economy are as follows: journey is the source domain and economy is the target domain. A goal or performance that a corporation aims to achieve in economy corresponds to the destination of a journey. The actions or strategies adopted in the course of a journey, such as stepping back, moving on and evacuation, also has its special meaning in the operation of an economy.

The start and the end of an economic activity are often expressed as the way that a traveler takes in his or her journey; let us take a look at the following examples: 
- Breaking More Barriers in Australia

- 奥巴马对华企在美投资设障（translation: Obama barricaded Chinese entreprises' investment in America)

- The housing market remained a hurdle for the expansion.

The words "barricade”, “设障” and “hurdle” in headline (28), (29) and (30) respectively are conceptual metaphor to give a vivid description of economic activities. These three words indicate the stagnation caused by different reasons in economic activities such as foreign trade and market. When economic activities are blocked or suspended, it is likely that one part in economic activities suffers financially or tends to be losing. The example of (30) shows that Chinese firm's investment is blocked by American government, so the trades of china will be influenced by the obstructions.

As we know that one can make various journeys, such as a train journey, a mountain journey, or a voyage journey. Such words as “扬帆出海” (set sail), “过河” (ford river), “探 索” (explore), “出发” (set out) appear in Chinese headlines. In addition, a journey is related to travelers, departure, speed, direction, obstacle and destination, and such journey elements are mapped onto economy field. Economy is structured in terms of journey, so it is easy for people to understand phenomena, events regarding economy domain.

\subsubsection{The Game Metaphor}

People from different cultural background may adopt different views and perspectives on their own culture. However, sometimes they may share the same personalities in common due to the overlapping of culture. For example, competitive spirit is one that both Chinese and English people aspire to achieve. People compete with each other through sports activities, or recreational activities, like The Tug of War, football, chess, etc. Originally, the terms in the game are confined to the game itself. With the development of world economy and globalization, the ambition to excel in the business world begins to be compared as the spirit of winning a game. So the game metaphor comes into being. It is quite often to pick out a game metaphor in economic news report, and news headlines. After selected some sampled economic news headlines, the author finds that the features of a game (the source domain) systematically mapped onto business, as indicated in the following analysis.

People plays game to battle against each other so as to win the championship. It also applies to the business circle. Companies running the same business and launching the same product do have the ambition to play a leading role in their trade of business. Thus, a competition between them to win the market share is inevitable. Look at the following examples:

- Japan Messaging App Aims to Rival Facebook

- IPad Mini Faces Rivals in India

- 亚航布局一线城市中国廉价航空迎来劲敌 (translation: Airasia's layout of cheap airline in Chinese 1st-tier cities brought in rivals)

As shown in the above examples, “竞争对手 (competitors)", “劲敌 (rivals)" and their English counterparts "rival", are initially used to describe the participants in a game, now when used in conceptual metaphors, they correspond with each other, the 
source domain (game) mapped onto the target domain (business).

\subsubsection{War Metaphor}

The correspondences between war and economy are as follows: war is the source domain and economy is the target domain. As is known to all, two parties-the offensive and the defensive are often involved in a war. The fight between them is just like the competition between two companies or organizations. The purpose of a war is to destroy the enemy's army and occupy his capital. And the purpose of business is to win more and more profits and monopolize the market. Entrepreneurs adopt all the strategies they can think out to realize their business objectives. The war and business may share the attributes and strategy so as to accomplish their aim. To be more specific, a war is involved in participants, leaders, soldier, war techniques, force, weapons, victims, casualties, failure or triumph. In fact, all the features of a war are systematically mapped onto economy. People fight against each other with the purpose of defeating others and win the leadership. Thus, a large number of words related to war can be mapped to business.

1) mapping of the entity from WAR domain to ECONOMY domain

The entities in the source domain of WAR are mapped systematically onto the entities in the source domain of ECONOMY For example, the battlefield is the market in the target domain.

2) mapping of the relationship from WAR domain to ECONOMY domain

The relationship in the source domain is mapped onto that in the target domain. The source domain of WAR is used in the economic activity to refer to the intense business competition, therefore, the relationship of war entrants is also mapped onto the participants in the economic activity

3) mapping of the features from WAR domain to ECONOMY domain

The features in the source domain are mapped onto the ones in the target domain.

After the successful mapping of the WAR metaphor, the features of war are exposed in vocabulary of economic news. War is adverse, aggressive, and strategic, so is the economic domain. In economic field, the economic competition is "fierce"; to win the competition requires all kinds of skills or "tactics" to achieve the "success" in the economic activity

4) mapping of the inference patterns from WAR domain to ECONOMY domain

In WAR metaphor, knowledge in the source domain is mapped onto that in the target domain or knowledge about a domain may enable us to make inference from it. As is known to all that in a war, there are at least two parties, and each of them have their own purpose of defeating the rivals. In the economic activity, the commercial rivals compete with each other with the help of the adoption of skills or tactics in order to gain the final benefits.

\subsection{Special Subcategories of Conceptual Metaphors in Chinese Economic News Headlines}

Metaphors are related to culture, different cultures and knowledge can generate specific 
experiences, which makes metaphorical concepts and expressions become diverse. Therefore, different conceptual metaphors arc found in Chinese.

\subsubsection{Student Metaphor}

For Chinese, school life plays an important part and many people want to change their life through studying and as a result, parents and students themselves put their emphasis on studying. therefore, this kind of experience is mapped onto the economic field to conceptualize the abstract ideas.

The difficult questions in their homework are mapped onto the problems that the companies or countries come across in economic development, such as “难题” (hard questions). “大考” (big test) and “答卷” (answer sheet) imply that in order to check the efficiency of the economic system, the companies or countries will have to take an examination and finish the paper. “座次” (seating) and “排名” (ranking) are mapped onto the ranking of countries of companies according to their economic power. “下课” (class dismission) means the teacher announces the class is over and so both teachers and students can have a rest. It is conceptualized as stopping one's work in a company or an organization.

\subsubsection{Marriage Metaphor}

China is a country with a history of over 5000 years. The feudal society occupied almost the half of the course of history, the socialist society is only more than one hundred years. Although women have been liberated, but now people's marriage ideas and customs are more or less affected by the influence of feudal marriage. In ancient times, women must follow her husband and nearly each woman want to marry a man with equal status or more than their privilege. In modern times, due to the rapid development of economy, a lot of people will also consider the material foundation as a priority factor for marriage. “门当户对” (a marriage between families of equal social rank) “联姻” (marriage), “配对” (match) and the others can be appeared on Chinese news headlines. For the same reason, the liberation of women, modern women no longer comply with marriage system of a female never marrying two husband and can be remarried. “改嫁” (remarry), “联姻” and “配对” are expressions describing the couple relationship. “改嫁” indicates the restructure of the company; “联姻” and “配 对” imply the cooperation between economic entities.

\subsubsection{Agriculture Metaphor}

Some terms of agriculture are used in Chinese economic news headlines. China is an agricultural country in the old times, people mainly grow grains to get all the food they need. Nowadays farmers still occupy a prodigious proportion in China. All the experience in growing grains can mapped onto other domains to help people to understand the abstract ideas. In the economic field, such metaphorical expressions are also found.

“深耕” (deep ploughing) and “精耕细作” (intensive cultivation) are words used in agriculture. The former refers to that the soil needs to be ploughed before sowing. Here the market is conceptualized as a farmland which needs to be ploughed in order to gain 
a better harvest. The latter means to work hard to produce good crops. In the economic field, the trust sectors are metaphorically become a farmland which needs the companies work hard. “播种” (sowing) means to sow seeds in the cultivated land, to irrigate with the appropriate water and to nourish with the appropriate fertilizer. In the economic field, the company has made some plans or actions to succeed in the future time. “收获” (harvest) is that a company harvest a great achievement.

\subsection{Special Subcategories of Conceptual Metaphors in English Economic News Headlines}

\subsubsection{Light Metaphor}

Light, as the essential part of human life, is one of perception metaphors used to conceptualize the economic activates. Light implies a good situation of economic development when it is mapped onto the economic domain.

- Analysts brighten outlook for sterling

- Brazil's banks lose shine as growth slows

"Brighten" and "shine" means the good situation of economic development. And "Brazil's banks lose shine" indicates that the banks' development is not in a situation with the economic growth slows.

\subsubsection{Health Metaphor}

In daily life, people pays close attention to their physical health and mental health, and at the same time mop these familiar health experience hint to the economic field. In Western countries, keeping strong is well praised and they do exercise to keep fit and healthy. This tendency in human life is used to conceptualize other concepts like economy. The economy is healthy or strong if it keeps developing normally and smoothly.

1) body health condition is economic operation condition

The most common used words in English to describe the body health are strong/ strength, weak/weakness, and in economic news headlines, the economy is good, the market will be strong and vital, when economic market is in recession, it will be weak, even very ill and suffer just like a patient in poor health.

2) mental health condition is economic operation condition

The most universal used words in English to describe mental health are stress, trouble, pressure and the like. Economic operation is regarded as a person with mental pressure. When in bad mood, people feel upset and suffer setback and pain. When economy is getting better, the stress will be eased and the market full of vitality, perking up again.

\section{Reasons for the Similarities and Differences between English and Chinese Conceptual Metaphors}

\subsection{Reasons for Similarities-Body Experience}

Similarities between English and Chinese mainly lie in the common bodily experience. As discussed in part three, mapping process between two different domains is not 
random, but deeply rooted in human beings' experience.

People themselves are the primary source domain, which helps them to conceptualize the world. People attribute human features such as their feelings, their health condition to the non-human things to understand the unfamiliar and abstract concepts. All these are shared by English and Chinese people. And the similarity of Up-Down metaphors between English and Chinese is also related to the same body experience of human beings. People's bodies usually keep straight, and if the emotion changes, the gesture will be influenced. When human beings are in good mood, they will cheer up and maintain the straight posture. The body experiences like those are mapped onto the economic field both in English and Chinese.

\subsection{Reasons for Differences}

The reasons for differences between the two languages lie in the cultural diversities. In some specific aspects, the conceptual metaphors are different because of specific cultures in different countries.

\subsubsection{Economic Patterns}

Economic pattern refers to the way of people to get materials for living and production. In Britain, agriculture is not so important, since it has less fertile land for farming as an island country. So, it is hard to find Agriculture Metaphors in English news headlines.

On the contrary, China, as a traditional agrarian society, mainly lives on agriculture and land. In ancient China, farming plays a decisive part for human beings, since people mainly grow grains to get all the food they need. Nowadays farmers still occupy a prodigious proportion in China. So agriculture exerts great influence in Chinese culture and language. All the experience in growing grains can mapped onto other domains to help people to understand abstract ideas and the metaphorical expressions created by farmers constitute a large part of metaphors in Chinese economic news headlines. For example, human beings use “深耕” to describe economic activities and imply that economy is agricultural activity.

\subsubsection{Religious Beliefs}

Religious beliefs of human beings have a great influence on culture and language, which will affect the conceptualization of abstract concepts and ideas.

China is a multi-religious country. Before the foundation of the new China, Buddhism, Taoism, Islam, Catholicism, Christianity (Protestant), and Confucian religion gradually formed a dominant status and a variety of other minorities religious and folk beliefs take second place.

Different from China, Christianity is the superior religion in Britain, and the Bible is the Christian classic and the main basis of western culture. Influences of the Bible have penetrated into all fields of society. Many metaphors and expressions come from the Bible like "Armageddon". "Armageddon" is a word from New Testament, which is a terrible battle or war some people think will lead to the total destruction of the world or the human race. In the economic field, it indicates that the fiscal cliff is not so severe 
which decides the whole economy, but a small problem which can be resolved soon.

\subsubsection{Historical Events}

The history of a culture is one reason for the differences of conceptual metaphors between Chinese and American. China is a country with a long civilization. The Chinese people have fought against wars and studied wars for thousands of years. While compared to China, America and Britain the two main English-speaking countries, have a relatively short history of war.

There are also other aspects influencing the differences between conceptual metaphors in the two languages, such as literature works and so on.

\subsubsection{Living Environments}

The environment that people live in also has a significant effect on the way of thinking and cognition, such as the climate of a country, the geographical location and so on. Affected by a certain kind of natural environment, people's language has certain features.

The diverse climates in different regions can influence the use of language and make people choose different expressions to conceptualize other abstract ideas even without being aware of their existence. Here the author will discuss how the climate of a country influences the conceptualization of economic phenomena. The similarities between the two languages lie in the universal human body experience on which conceptual metaphors depend. And the differences between them mostly result from the cultural diversity and physic environment.

\section{Conclusion}

The main mechanism of metaphor is through which people understand abstract concepts and abstract reasoning. There are some similarities and subtle differences between them. The similarities they shared are due to a common cognitive basis they shared. The differences between the conceptual metaphors in English and Chinese economic news headlines are due to the diverse cultural context and natural physical environment, where people involved in, leading to the different use of conceptual metaphors in English and Chinese economic news headlines.

Some special metaphors respectively exist in Chinese and English economic new headlines. The Marriage Metaphor in the category of Human Being Metaphor is a representation of distinctive feature that conceptual metaphor has got in Chinese economic news headlines, while Light Metaphor only exists in English economic news headlines.

\section{References}

Boers, F. (2000). Enhancing Metaphorical Awareness on Specialized Reading. English for Specific Purposes Journal, 19, 149-165.

Henderson, W. (1982). Metaphor in Economics. Economies (Winter), 18, 147-153.

Henderson, W. (1986). Metaphor in Economics. In M. Coulthard (Ed.), Talking about Econom- 
ics Text (pp. 109-127). Birmingham: University of Birmingham English Language Research.

Lakoff, G., \& Johnson, M. (1980). Metaphors We Live by. Chicago and London: University of Chicago Press.

Lakoff, G., \& Johnson, M. (2003). Metaphors We Live by. London: University of Chicago Press. http://dx.doi.org/10.7208/chicago/9780226470993.001.0001

McCloskey, D. N. (1983). The Rhetoric of Economics. Journal of Economic Literature, 21, 481517.

McCloskey, D. N. (Ed.). (1990). The Consequences of Economic Rhetoric (pp. 60-70). Cambridge: Cambridge University Press.

Koller, V. (2004). Metaphor and Gender in Business Discourse: A Critical Cognitive Study. New York: Palgrave Macmillan. http://dx.doi.org/10.1057/9780230511286

Koller, V. (2008). Brothers in Arms: Contradictory Metaphors in Contemporary Marketing Discourse. Amsterdam: John Benjamin's Publishing Company.

Submit or recommend next manuscript to SCIRP and we will provide best service for you:

Accepting pre-submission inquiries through Email, Facebook, LinkedIn, Twitter, etc. A wide selection of journals (inclusive of 9 subjects, more than 200 journals)

Providing 24-hour high-quality service

User-friendly online submission system

Fair and swift peer-review system

Efficient typesetting and proofreading procedure

Display of the result of downloads and visits, as well as the number of cited articles

Maximum dissemination of your research work

Submit your manuscript at: http://papersubmission.scirp.org/

Or contact ce@scirp.org 